\title{
Erratum: Design and Evaluation of Interaction Technology for Medical Team Meetings
}

\author{
Alex Olwal, Oscar Frykholm, Kristina Groth, and Jonas Moll \\ School of Computer Science and Communication \\ KTH (Royal Institute of Technology), Stockholm, Sweden \\ \{alx, frykholm, kicki, jomol\}@csc.kth.se
}

P. Campos et al. (Eds.): INTERACT 2011, Part I, LNCS 6946, pp. 505--522, 2011.

(C) IFIP International Federation for Information Processing 2011

DOI 10.1007/978-3-642-23774-4_51

By mistake the following errors were introduced in the paper:

- $\quad$ Figure 1 was moved to the top of p. 506. It should have been placed on the bottom of p. 505.

- $\quad$ Figure 6 was moved to the middle of p. 513. It should have been placed on the bottom of p. 513 .

- $\quad$ The end period of the captions of Figures 4 and 5 was removed.

- The authors in reference 18 were not formatted correctly. The correct version is: "Ratib, O., McCoy, J.M., McGill, D.R., Li, M., Brown, A." 